\title{
Metodologia para identificação de bactérias do solo através da manipulação de cores primárias
}

\author{
Thiago Alonso Merici', Victor Barbosa Saraiva', Alexandre Peixoto do Carmo ${ }^{1}$
}

\author{
$\checkmark \underline{\text { thiago.merici@ifmg.edu.br }}$
}

\author{
1. Instituto Federal de Educação, Ciência e Tecnologia de Minas Gerais - Campus Betim, Avenida Professor Mário \\ Werneck, 2590, Buritis, Minas Gerais. \\ 2. Instituto Federal Fluminense, Avenida Souza Mota, 350, Campos dos ${ }^{\text {Goitacazes }}$, Rio de Janeiro, Brasil.
}

\section{Histórico do Artigo:}

Recebido: 25 de maio de 2017

Aceito: 21 de novembro de 2017

Publicado: 18 de julho de 2017

Resumo: Por possuírem funções vitais na natureza, as bactérias são constante objeto de estudos. Elas são aplicadas para degradar poluentes em um processo de biorremediação, em áreas contaminadas, muito comuns em regiões litorâneas, que estão sempre sendo agredidas em consequência da exploração e transporte de petróleo, e na agricultura com a finalidade de melhorar, em vários aspectos, a qualidade das técnicas de cultivo e dos produtos cultivados. Algumas bactérias encontradas na restinga de Massambaba em Arraial do Cabo, RJ, possuem características relacionadas às suas cores que chamaram a atenção dos pesquisadores do Laboratório de Ecotoxicologia e Microbiologia Ambiental, LEMAM. A luz é uma radiação eletromagnética que pode ser percebida visualmente através de cores quando esta interage com o meio. Alguns sistemas podem eliminar as características subjetivas de interpretação das cores, criando padrões de representação para as mesmas. Este artigo é sobre um estudo experimental e utiliza a manipulação das cores primárias verificadas em fotografias digitais de culturas de bactérias. As cores são transformadas matematicamente, transitando entre espaços de representação de cores sendo identificadas em cada um deles e representadas no cubo de cores RGB e no diagrama de cromaticidade. Através da metodologia proposta no trabalho, foi possível verificar os comprimentos de onda predominantes na cor de cada espécie, assim como identificá-las por suas localizações no diagrama de cromaticidade.

Palavras-chave: Bactérias, Colorimetria, Espectro Eletromagnético, Diagrama de Cromaticidade.

\section{Methodology for identification of soil bacteria by manipulation of primary colors}

\begin{abstract}
Due to their vital functions in nature, bacteria are the subject of constant study. They are applied to degrade pollutants in a process of bioremediation, in contaminated areas, very common in coastal regions, constantly attacked by oil exploration and transportation, and in agriculture in order to improve the quality of cultivation techniques as well as of the cultivated products. Some bacteria found in the Massambaba sandback in Arraial do Cabo, RJ, have characteristics related to their colors that attracted the attention of the researchers of the Laboratory of Ecotoxicology and Environmental Microbiology, LEMAM. Light is an electromagnetic radiation that can be perceived visually through colors when it interacts with the environment. Some systems can eliminate the subjective characteristics of color interpretation, creating patterns of representation for them. This article is about an experimental study, and uses the manipulation of the primary colors verified in digital photographs of cultures of bacteria. The colors are transformed mathematically, transiting between spaces of color representation being identified in each of them and represented in the RGB color cube and the chromaticity diagram. Through the methodology proposed in this work, it was possible to verify the predominant wavelengths in the color of each species, as well as to identify them by their locations in the chromaticity diagram..
\end{abstract}

Keywords: Bacteria, Colorimetry, Electromagnetic Spectrum, Chromaticity Diagram. 


\title{
Metodología para identificación de bacterias del suelo a través de la manipulación de colores primarios
}

\begin{abstract}
Resumen: Por poseer funciones vitales en la naturaleza, las bacterias son constantes objeto de estudios. Se aplican para degradar los contaminantes, en un proceso de biorremediación, en las áreas contaminadas, muy comunes en regiones costeras que son siempre agredidas por la explotación y el transporte de petróleo, y en la agricultura con el fin de mejorar, en varios aspectos, la calidad de las técnicas de cultivo y de los productos cultivados. Algunas bacterias encontradas en la restinga de Massambaba en Arraial do Cabo, RJ, poseen características relacionadas a sus colores que llamaron la atención de los investigadores del Laboratorio de Ecotoxicologia y Microbiologia Ambiental, LEMAM. La luz es una radiación electromagnética que puede ser percibida visualmente por sus colores una vez que ésta interactúa con el medio. Algunos sistemas pueden eliminar las características subjetivas de interpretación de los colores, creando patrones de representación para las mismas. Este artículo es sobre un estudio experimental y utiliza la manipulación de los colores primarios verificados en fotografías digitales de cultivos de bacterias. Los colores son transformados matemáticamente, transitando entre espacios de representación de colores siendo identificados en cada uno de ellos y representados en el cubo de colores RGB y en el diagrama de cromaticidad. Con la metodología propuesta en el trabajo fue posible verificar las longitudes de onda predominantes en el color de cada especie, así como identificarlas por sus ubicaciones en el diagrama de cromaticidad.

Palabras clave: Bacterias, Colorimetría, Espectro Electromagnético, Diagrama de Cromaticidad.
\end{abstract}

\section{INTRODUÇÃ0}

As bactérias exercem um papel extremamente importante na natureza, atuando em processos como a fotossíntese, decomposição de matéria orgânica e até mesmo na regulação de funções orgânicas em plantas e animais. Com o aumento da preocupação com as questões ambientais, outras funções que podem ser exercidas por bactérias são percebidas e estudadas com o intuito de amenizar problemas de poluição e degradação do meio ambiente assim como melhorar a qualidade dos processos e produtos agrícolas. Em regiões litorâneas é bastante comum que solos e águas sejam contaminados em decorrência dos processos de exploração do petróleo. Existem muitos estudos que sugerem a aplicação de bactérias nessas áreas como estratégia de descontaminação, uma vez que algumas apresentam propriedades de degradação de componentes do petróleo. Este processo é chamado de biorremediação e pode ser aplicado em diversas situações visando à melhoria de áreas contaminadas por uma enorme gama de agentes poluidores (RIBEIR0, 1993). A tecnologia de biorremediação usa microrganismos para reduzir, eliminar, conter ou transformar contaminantes presentes em solos, sedimentos, água e ar em substâncias benignas (SHAH, 2014;ADAMSet al., 2015).

Outra área onde se tem aplicado bactérias é na agricultura, visando o fortalecimento de plantas, a diminuição do uso de agrotóxicos e o controle de pragas. Esses microrganismos têm sido estudados para serem utilizados na degradação de pesticidas como os organofosforados (VELÁZQUEZ-FERNÁNDEZ et al., 2012). Enzimas de biodegradação de 
bactérias desempenham um papel fundamental nos processos de biorremediação e seu conhecimento pode ajudar na concepção ou escolha da estratégia mais adequada (LOVLEY; LLOYD, 2000). Desta forma, fica evidente a preocupação e a motivação que vem sendo empregada no estudo desses microrganismos (AZEVED0; ARAUJ0; MACCHERONI, 2000).

Uma tecnologia eficiente aplicada na identificação de bactérias é a Reação em Cadeia da Polimerase, PCR, capaz de identificar até mesmo linhagens diferentes dentro da mesma espécie (REIS JUNIOR et al., 1998). No entanto, existe uma busca por técnicas acessíveis que possibilitem uma identificação preliminar com rapidez e baixo custo, contrapondo uma caracterização genotípica a uma caracterização fenotípica, que leva em consideração o padrão de cultivo dos microrganismos e sua interação com o ambiente.

Como ferramenta para identificação de microrganismos, é comum a aplicação de métodos espectroscópicos, sendo que a maioria destas aplicações acontece na faixa do infravermelho (DELWICHE; MASSIE, 1996; HANS, 2003; MIRALBES, 2004; ARGYRIA et al., 2010). No entanto, algumas bactérias coletadas pela equipe do Laboratório de Ecotoxicologia e Microbiologia Ambiental, LEMAM, apresentaram colorações bastante definidas, o que despertou o interesse de realizar trabalhos de identificação e caracterização das mesmas na região do visível.

Sendo assim, o foco deste estudo está na metodologia e na técnica de identificação das bactérias e não nas espécies, cultivo ou crescimento das mesmas. Por este motivo as bactérias estudadas serão tratadas por nomes genéricos, A, B, C e D. Não se dará ênfase aos processos biológicos, mas sim aos processos físicos que possibilitem o desenvolvimento da técnica para alcançar os objetivos em questão. Será então apresentada uma proposta de trabalho que sugere uma metodologia inovadora, estudando as bactérias em meio sólido de cultura, utilizando fotos digitais das mesmas e explorando suas características cromáticas baseado em um processo de formação das cores a partir das cores primárias, valendo-se de transformações matemáticas e mudanças de sistemas de representação de cores para criar um padrão de identificação fenotípica em regiões delimitadas em um diagrama de cromaticidade.

As cores podem ser percebidas de formas distintas por indivíduos diferentes. 0 termo cor é entendido como uma sensação captada pelo olho e conduzida até o cérebro através de impulsos nervosos. Assim como todos os sentidos, essa sensibilidade é subjetiva e apresenta 
Metodologia para identificação de bactérias do solo através da manipulação de cores primárias

variações entre os seres humanos (MEYER; ZOLLINGER, 1998). De fato, a cor pode ser considerada uma dimensão adicional na identificação dos objetos, no entanto, ela não é uma propriedade que pertence aos materiais e sim um atributo perceptivo do indivíduo observador. As cores percebidas correspondem a uma resposta produzida no cérebro após a captação de luz do ambiente (BRINDLEY, 1953). Contudo, existem padrões que permitem definir uma cor independentemente das particularidades do observador. Através da colorimetria (ciência de medição de cores), é possível expressar quantitativamente uma cor. Por meio de transformações matemáticas atribui-se a cada cor um valor numérico, codificando a mesma e eliminando a subjetividade em sua percepção (CAVALCANTI, 2000). Em 1931, a Comissão Internacional de Iluminação, CIE, criou a codificação RGB (Red, Green, Blue, para o vermelho, o verde e 0 azul), que representa o espaço de todas as cores que podem ser obtidas através dessas três radiações de cores monocromáticas (JACK; MACDONALD; FREEMAN, 1994).

\section{CONTEXTUALIZAÇ̃̃O DO TEMA}

\section{Colorimetria e sistemas de cores}

Para trabalhar com as cores é necessário entendê-las e padronizá-las. Por este motivo, desenvolveram-se estudos com a finalidade de representar descrever e medir as cores. Segundo Gomes e Velho (1998), a colorimetria é a ciência que representa as cores com medidas físicas. No entanto, pelo fato das cores dos objetos dependerem da visão, da luz e de particularidades do indivíduo, elas tornam-se um atributo subjetivo e podem, de maneira geral, ser descritas por medidas perceptíveis.

As medidas físicas utilizam conceitos físicos teóricos para representar as cores, como 0 estudo da superposição das ondas monocromáticas do espectro, uma vez que este processo permite a obtenção das demais cores na região do visível (RESNICK; HALLIDAY; WALKER, 2010). Estes conceitos afirmam que a cor é definida pela frequência da luz, contudo, as faixas de cores são comumente representadas por seus comprimentos de onda. Em decorrência de tal fato, vários sistemas de medição surgiram baseados em estudos das cores primárias, com 0 intuito de padronizar a representação das cores, como o sistema CIE-RGB e o CIE-XYZ, que serão abordados mais adiante neste trabalho. 
Já as medidas perceptíveis abordam aspectos genéricos relativos à cor estudada. A percepção da luz pelos olhos se dá pela luminância, saturação e tonalidade da cor (GONZALEZ; WO0DS, 2003). A luminância está diretamente relacionada com a quantidade de energia da luz percebida por um observador. Este conceito é popularmente conhecido como brilho da cor (G0NZALEZ; WOODS, 2003). Para melhor entender o conceito de luminância, faz-se necessário uma abordagem física quantitativa. Quando uma luz monocromática com 1 watt de potência atinge 0 olho humano, a resposta que este apresenta para o brilho percebido não é constante quando varia-se o comprimento de onda (CAVALCANTI 2000). Como mostra o Gráficol, a resposta é máxima na faixa do verde, no comprimento de onda de $555 \mathrm{~nm}$.

Gráfico 1 - Sensibilidade relativa ao brilho com resposta máxima na faixa do verde.

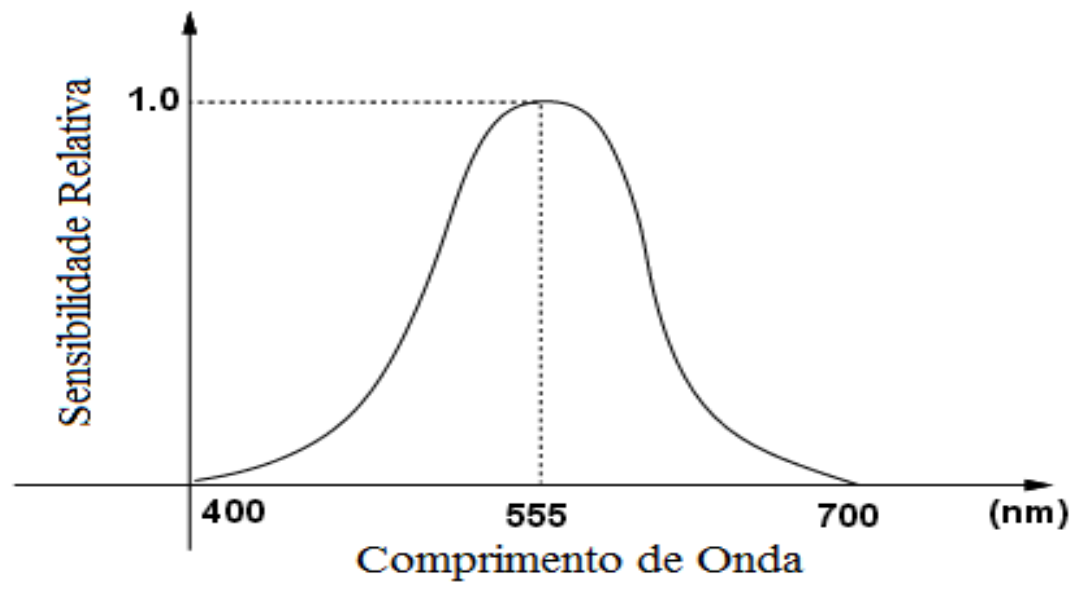

Fonte: Cavalcanti (2000).

0 grau de pureza da cor é medido pela saturação da mesma, que significa uma graduação entre a cor pura, monocromática e a luz branca, sendo que a saturação é máxima na luz monocromática e mínima na luz branca, onde na verdade ela pode ser considerada nula. É importante frisar que o brilho não possui definição uniforme na literatura, uma vez que este possui caráter subjetivo praticamente impossível de ser medido, no entanto, é consenso que ele está diretamente ligado ao conceito de luminância da imagem e este termo é utilizado para emissão e reflexão da luz em corpos luminosos ou iluminados (GOMES; VELHO, 1998). Já a tonalidade de uma cor é a grandeza que diferencia uma cor de outra ou a predominância de uma delas em uma cor indefinida, ou seja, a cor é identificada pela cor monocromática mais próxima a ela. Este processo acontece por meio de comparações com cores previamente 

primárias

conhecidas e bem definidas no espectro visível. Quando juntas, saturação e tonalidade formam a crominância, grandeza que não depende do brilho e consequentemente é invariante a este (GOMES; VELHO, 1998).

Um dos modelos mais utilizados em representação de cores é provavelmente o espaço RGB. Este modelo é baseado no princípio de que vários efeitos cromáticos podem ser obtidos incidindo a luz branca em filtros vermelho, verde e azul, produzindo feixes de luz nas cores específicas e produzindo cores secundárias através da superposição das primeiras (S0UT0 2000), como mostra a Figura 1.
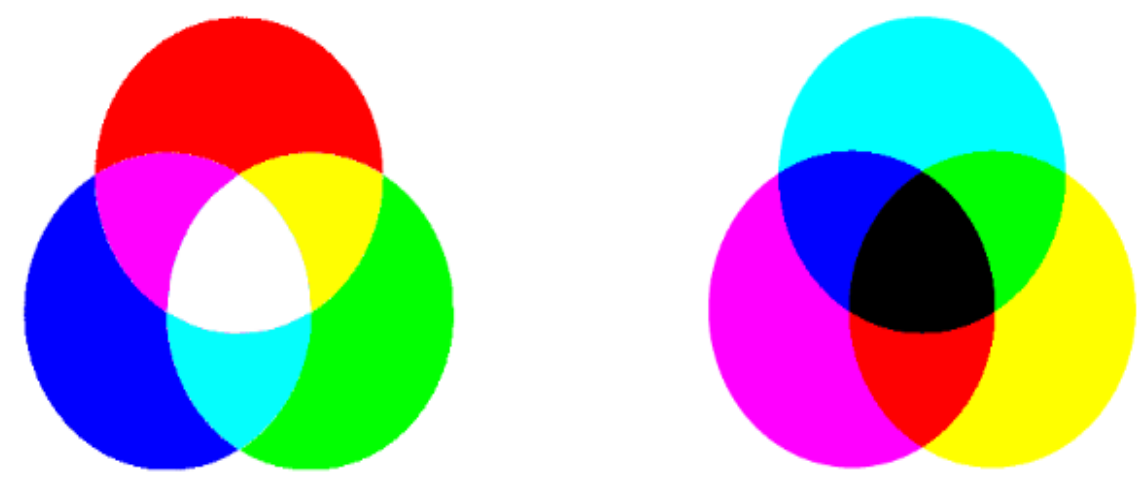

Figura 1 - Síntese aditiva das cores primárias e subtrativa das cores secundárias. Fonte: Modificado de Envi (2000).

A luz branca é obtida na interseção das luzes projetadas pelos três círculos, sendo, segundo Souto (2000), uma composição entre as cores primárias, que são assim definidas por não ser possível reproduzi-las a partir de misturas de outras cores. Já as outras cores podem ser obtidas por combinações variáveis das cores primárias.

0 espaço de cores RGB é normalmente representado por uma figura geométrica denominada cubo de cores. Representando-0 com suas arestas medindo uma unidade e posicionando-o da forma mostrada no Gráfico 2, temos a cor preta representada na origem e a cor branca está no vértice de coordenadas $(1,1,1)$, as outras cores primárias se localizam nos vértices que estão sobre os eixos, enquanto os outros vértices abrigam as cores complementares de cada cor primária. Já no interior do cubo, cada ponto representa uma cor 
formada pela composição das três cores primárias, vermelho, verde e azul, com seus valores variando entre 0 e 1 (SOUT0 2000).

Gráfico 2 - Espaço representativo de cores RGB.

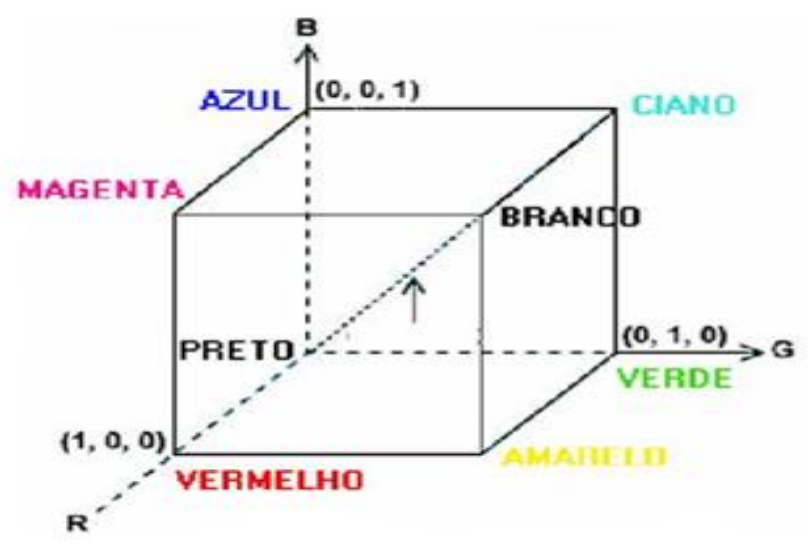

Fonte: Souto (2000).

Ainda segundo Souto (2000), a diagonal principal do cubo, que liga o vértice que representa a cor preta ao vértice que representa a cor branca, representa os tons de cinza. Como qualquer ponto nesta diagonal está equidistante dos vértices sobre os eixos, pode-se concluir que esses tons de cinza são formados por quantidades iguais de todas as cores primárias.

Os comprimentos de onda definidos para o sistema RGB apresentam uma diferença em relação aos comprimentos de onda observados pelos cones humanos. Essa diferença, que sofreu variações ao longo dos anos, é maior para o vermelho, diminuindo para o verde e 0 azul respectivamente (LOPES, 2003), como mostra a Tabela 1.

Tabela 1 - Comprimentos de onda das cores primárias.

\begin{tabular}{ccc}
\hline Cor & $\begin{array}{c}\text { Comprimento de 0nda } \\
\text { RGB }\end{array}$ & $\begin{array}{c}\text { Comprimento de 0ndas } \\
\text { Cones }\end{array}$ \\
\hline Vermelho & $700 \mathrm{~nm}$ & $570 \mathrm{~nm}$ \\
Verde & $546 \mathrm{~nm}$ & $535 \mathrm{~nm}$ \\
Azul & $435,8 \mathrm{~nm}$ & $445 \mathrm{~nm}$ \\
\hline
\end{tabular}

Fonte: Própria. 

primárias

Devido a essa diferença, quando, por exemplo, em um monitor de computador, misturavam-se as três luzes emitidas por tubos de raios catódicos, a cor pretendida não correspondia à cor detectada pelo olho humano, tendo sido, por este motivo, necessário mudar as proporções das intensidades das cores primárias emitidas. No entanto, ao mudar essas proporções, pode-se assumir valores de tri-estímulos negativos para alguns comprimentos de onda, como mostra o Gráfico 3, o que impossibilita, neste sistema, a reprodução de todas as cores do espectro visível por computadores (LOPES, 2003).

Gráfico 3 - Valores do tri-estímulos para as cores primárias no sistema CIE-RGB.

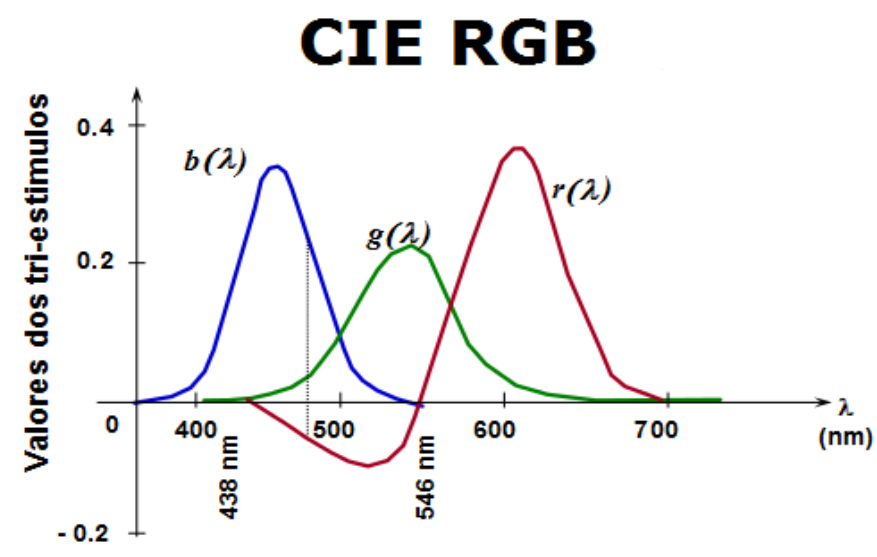

Fonte: Lopes (2003).

Para corrigir este problema a CIE, em 1931, criou um novo modelo de representação de cores, chamado de espaço X, Y, Z, onde as cores primárias são virtuais, não correspondendo mais às cores visíveis, obtidas através de transformações onde todas as componentes produzem valores de tri-estímulos sempre positivos, tornando possível a reprodução de todos os comprimentos de onda do espectro visível. Devido à incapacidade de reproduzir todas as cores visíveis utilizando o modelo CIE-RGB, foi criado o modelo CIE-XYZ, que foi definido de forma que as funções de ajuste de cor de suas cores primárias tivessem sempre valores positivos (WRIGHT, 1941; WYSZECKI; STILES, 1982). As curvas de ajuste deste novo modelo estão expressas no Gráfico 4. 
Gráfico 4 - Valores dos tri-estímulos para as cores primarias no sistema CIE-XYZ.

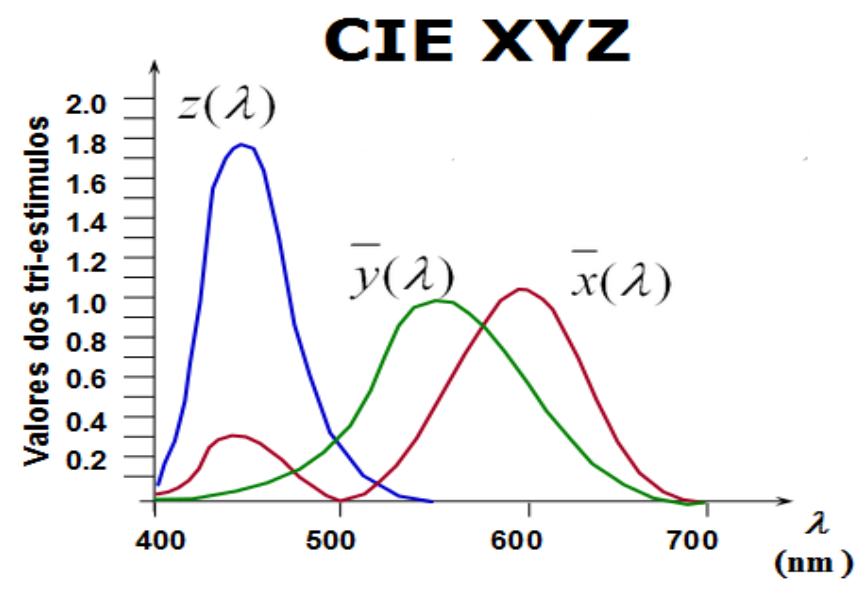

Fonte: Lopes (2003).

0 sistema CIE-XYZ foi definido de forma que duas cores primárias, X e Z tivessem luminância nula. Assim apenas a componente $Y$ tem influência da luminância. A reta XY é formada com o objetivo de se obter o maior número possível de cores espectrais, com algumas coordenadas de cromaticidade nula e a reta YZ é traçada de forma a minimizar a área do triângulo formado neste processo. As cores primárias X, Y e Z estão situadas nos vértices desse triângulo como mostrado no Gráfico 5. Nota-se que todas as cores do sistema RGB estão compreendidas no sistema XYZ (CAVALCANTI 2000).

Gráfico 5 - Espaço CIE-XYZ abrangendo o espaço CIE-RGB.

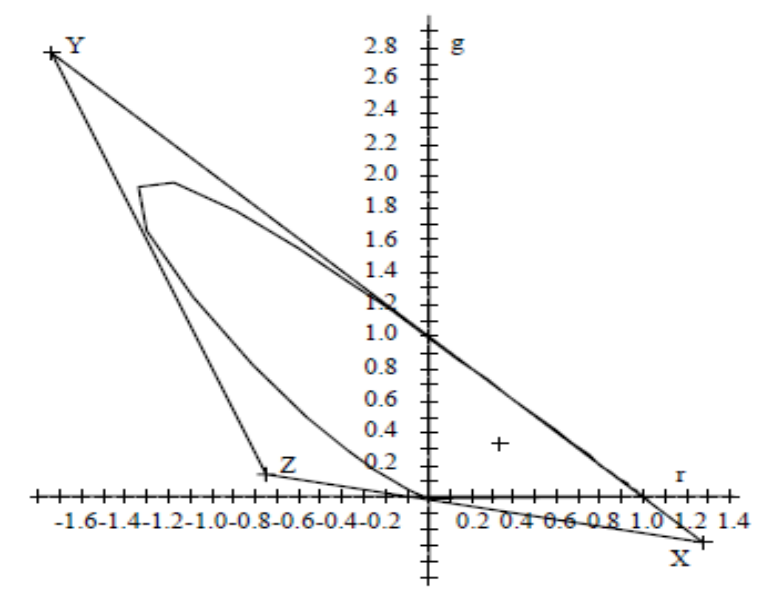

Fonte: Cavalcanti (2000). 
Metodologia para identificação de bactérias do solo através da manipulação de cores primárias

As cores primárias deste novo sistema assumem então as coordenadas, em relação ao sistema RGB, apresentadas na Tabela 2.

Tabela 2: Coordenadas de cromaticidade do sistema XYZ.

\begin{tabular}{cccc}
\hline Cor & $\boldsymbol{r}$ & $\boldsymbol{g}$ & $\boldsymbol{b}$ \\
\hline $\mathrm{X}$ & 1,2750 & $-0,2778$ & 0,0028 \\
$\mathrm{Y}$ & & & \\
& $-1,7393$ & 2,7673 & $-0,0280$ \\
$\mathrm{Z}$ & $-0,7431$ & 0,1409 & 1,6022 \\
& & & \\
\hline
\end{tabular}

Fonte: Própria.

\section{Diagrama de cromaticidade}

0 diagrama de cromaticidade é construído a partir do sistema CIE-xyY. Ele consiste na representação das cores criadas por uma luz ou mistura de luzes no plano xy, a fim de identificar uma cor por comparação aos padrões de cores já definidos. 0 diagrama ordena as cores, tentando organizá-las em um espaço uniforme, de acordo com nossa percepção e sensibilidade, no entanto, distâncias iguais no diagrama não correspondem a distâncias perceptuais iguais (LEE, 2008). OGráfico 6 apresenta diagramas de cromaticidade com todos os valores de cromaticidade para as cores visíveis. Como a luminosidade não é considerada neste diagrama, cores com intensidades luminosas ou brilhos diferentes ocupam o mesmo ponto no gráfico se possuírem coordenadas de cromaticidade iguais.

Neste diagrama, as cores puras do espectro visível localizam-se nas bordas. Como já dito anteriormente, as cores puras apresentam máxima saturação. Sendo assim, pode-se definir o sentido de saturação no diagrama pelas setas representadas no gráfico. Se as setas forem percorridas no sentido oposto, será encontrado o ponto de saturação mínima ou nula, que corresponde à luz branca. Este ponto se localiza, aproximadamente, sobre as coordenadas de valor $1 / 3$. Cores puras, como o magenta, que não se encontram no espectro visível, estão situadas na reta que forma a base do diagrama (LOPES, 2003). Uma propriedade muito relevante do diagrama de cromaticidade é a linearidade que ele apresenta.Sendo assim, um segmento de reta que une dois pontos que representem duas cores quaisquer, contém todas as 
cores possíveis de se obter pela mistura dessas duas cores nas proporções necessárias para formar a cor desejada(LOPES, 2003).

Gráfico 6 - À esquerda o diagrama de cromaticidade e, à direita o diagrama com o sentido da saturação.
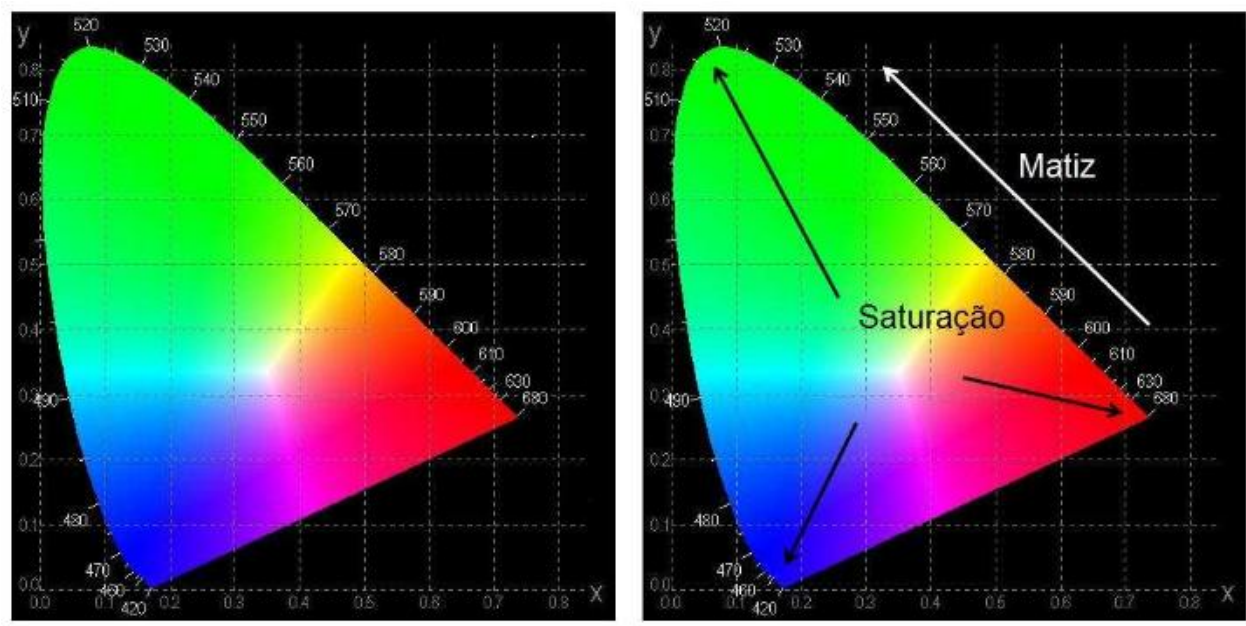

Fonte: Modificado de Werner (1998).

\section{MATERIAL E MÉTODOS}

Este trabalho visa apresentar um método que utiliza o modelo de representação de cores CIE-RGB na identificação de bactérias cujas colônias apresentam colorações específicas e bastante definidas. É importante salientar que o objetivo principal é criar o método e mostrar sua aplicabilidade no processo de identificação. As bactérias estão em segundo plano e, por este motivo, não serão tratadas aqui pelas denominações de suas espécies e sim por denominações genéricas. As culturas foram crescidas em meio sólido (LB + Ágar 2\%, pH 7,5) devidamente identificadas e incubadas por 24 horas a uma temperatura de $25^{\circ} \mathrm{C}$.

Foram submetidas a este estudo quatro espécies distintas, representadas pelas letras A, B, C e D, com o objetivo de eliminar possíveis influências dos nomes de suas cores perceptuais, dando foco para as cores, obtidas pelo método apresentado.

A identificação será feita pela localização das cores, devidamente codificadas, observadas nas colônias em um diagrama de cromaticidade CIE-xyY. Para tornar possível este feito será necessário entender os conceitos relacionados às cores e à formação das mesmas 

primárias

nos objetos, assim como os fenômenos de absorção e reflexão relacionados às cores, além de realizar transformações matemáticas minimizando ao máximo a subjetividade da interpretação das mesmas.

A Figura 2 mostra algumas bactérias que serão estudadas, com a finalidade de justificar a escolha de uma metodologia inovadora, que busca trabalhar com microrganismos explorando suas cores, criando padrões de identificação que utilizem processos rápidos e eficazes para este fim.

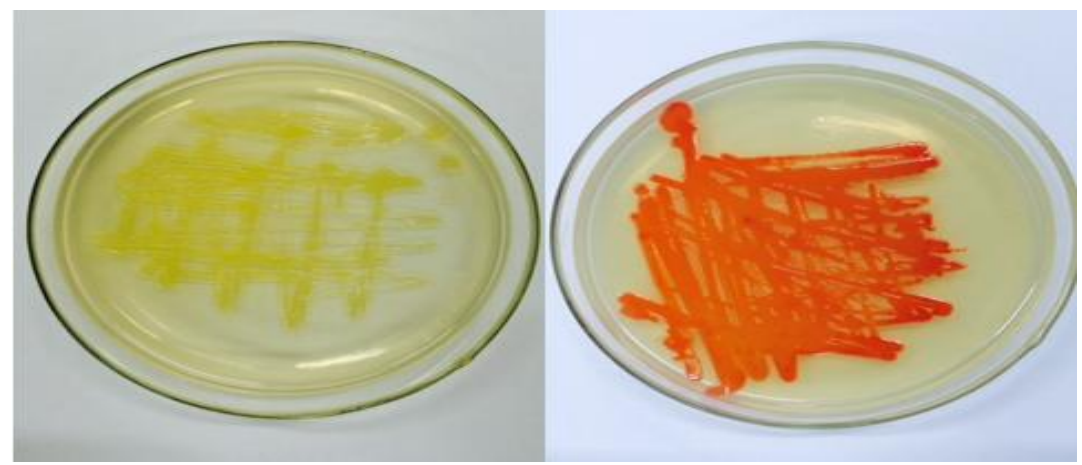

Figura 2 - Bactérias da restinga de Massambaba, Arraial do Cabo, Rio de Janeiro. Fonte: Própria.

Para realização dos experimentos foram utilizados softwares e aplicativos gratuitos de fácil acesso, com o objetivo de tornar os experimentos viáveis e executáveis com simplicidade e rapidez garantindo resultados confiáveis. As fotografias foram tiradas com uma Câmera

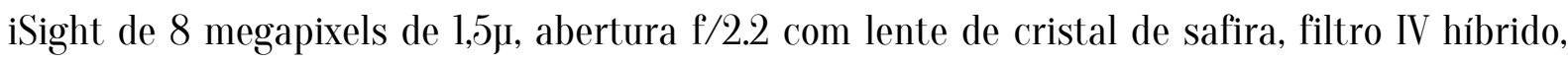
sensor de retroiluminação, estabilizador de imagem e foco automático e, para identificação das cores, foi usado o aplicativo ColorHelper 4 Men www.codete.co Ferramentas, disponível $\begin{array}{llll}\text { gratuitamente } & \text { para } & \text { download }\end{array}$ https://play.google.com/store/apps/details?id=co.codete.android.colorhelper\&hl=pt BR. $\quad$ Este aplicativo permite que a foto seja tirada através dele ou que a mesma seja recuperada da biblioteca de arquivos da câmera. Estando definida a imagem, podem-se selecionar pontos específicos da fotografia com um grau de precisão, fornecida pelo aplicativo, que varia em uma escala de 1 a 20, garantindo assim, que as cores analisadas foram exatamente do ponto pretendido no objeto. Neste experimento foi utilizada a menor escala, que permitiu analisar a menor região possível da figura. 0 aplicativo então fornece a composição da cor e da região 
selecionada em RGB, assim como a identificação dessa cor em hexadecimal. A Figura 3 exemplifica as funções citadas acima.

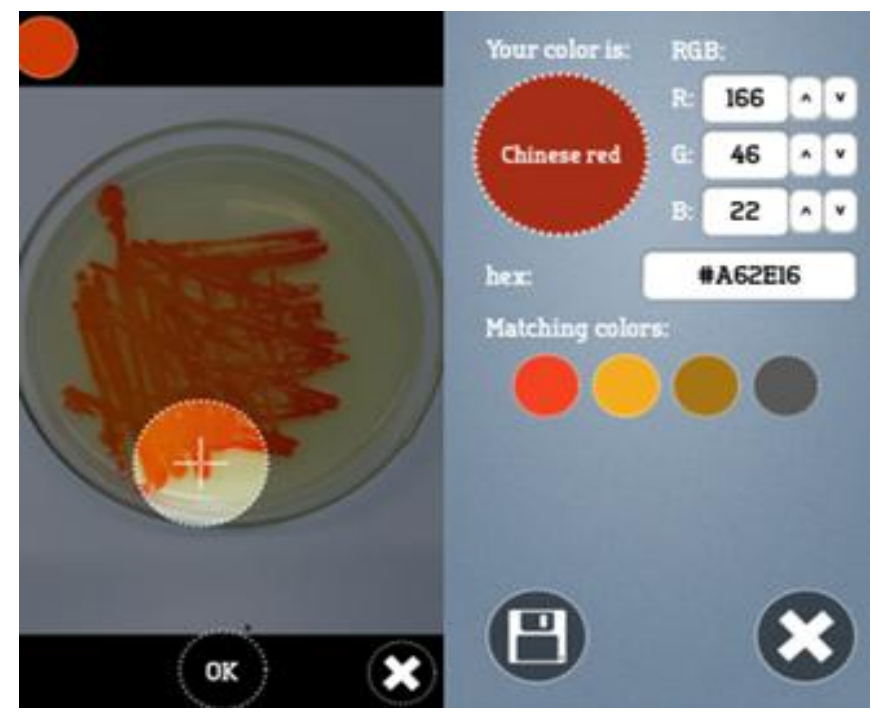

Figura 3 - Aplicativo de medição dos valores das cores primárias RGB. Fonte: Própria.

Para a localização no cubo de cores, foi utilizado o software gratuito denominado PaColorCube, versão 1.0, Cubo de Cores, disponível on-line em www.uff.br, na página denominada "0 Sistema RGB e o Cubo de Cores". Neste programa basta fornecer os valores das componentes RGB e a cor estudada é posicionada no cubo.Já para a representação das cores no diagrama de cromaticidade, foi utilizado o software Color Calculator, desenvolvido pela empresa Radiant Imaging, disponível gratuitamente para download no site da empresa, no endereço http://www.radiantzemax.com. 0 programa fornece o diagrama de cromaticidade quando lhe são dadas as coordenadas x e y, obtidas das coordenadas de cromaticidade através dos processos de transformações já descritos. Após este passo, a cor desejada é identificada em pontos no diagrama de cromaticidade. 0 gráfico 7 dá um exemplo de algumas cores representadas no cubo e mostra a imagem do diagrama de cromaticidade utilizado. 

primárias

Gráfico 7 - Software representativo do cubo de cores RGB e imagem do diagrama de cromaticidade no software Color Calculator.

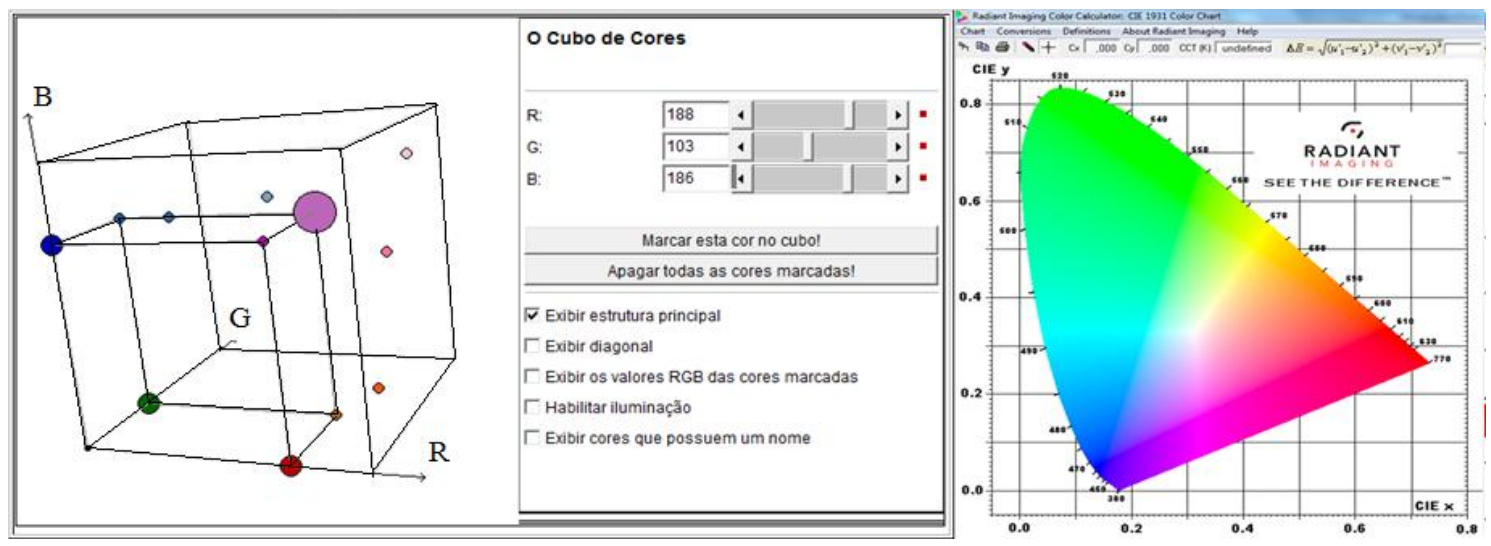

Fonte: Própria.

Além de representar as cores no diagrama de cromaticidade CIE-xyY, o software também faz conversões de unidades de cromaticidade e representações em outros sistemas.

0 experimento é realizado em conjunto com a equipe do Laboratório de Ecotoxicologia e Microbiologia Ambiental (LEMAM), que faz a coleta e cultivo das bactérias, obedecendo a protocolos e padrões específicos. Estes processos não serão tratados aqui, uma vez que o foco deste trabalho está nos experimentos de identificação das bactérias através de processos físicos.

As bactérias são levadas então para o laboratório de Física, onde são tiradas as fotografias, sempre no mesmo local e com o mesmo padrão de iluminação.A luz do sol e as luzes de lâmpadas comuns são consideradas luzes brancas e por este motivo são chamadas de iluminantes padrão. A distância entre a câmera e a placa foi ajustada experimentalmente, para uma melhor captação da imagem, para 0 valor de $10 \mathrm{~cm}$.

0 processo seguinte se deu através do aplicativo ColorHelper, que fornece a composição da cor em RGB do ponto escolhido. 0 procedimento foi realizado em cinco placas e em cada placa foram escolhidos cinco pontos para análise. Cada placa forneceu uma informação de cor para o experimento, uma vez que dos cinco pontos citados foi calculada uma média aritmética simples com o objetivo de aumentar a confiabilidade da cor e a pertinência desta à colônia estudada.

Uma das maneiras proposta para identificar um padrão que especifique as espécies quanto as suas cores foi a representação destas no cubo de cores RGB. Este primeiro 
procedimento é bastante simples, uma vez que a entrada de dados no programa é feita com os próprios valores em RGB. Foram então analisadas as posições das cores que representam cada espécie dentro do cubo, relacionando a proximidade dos pontos que representam espécies iguais e a distância destes com os que representam espécies diferentes, buscando conclusões lógicas para estes resultados.

Para a representação das cores no diagrama de cromaticidade, são necessários alguns procedimentos de conversões de sistemas. Estes foram descritos detalhadamente na revisão da literatura. As cores que, a princípio, estão no sistema CIE-RGB, são normalizadas e convertidas para o sistema CIE-XYZ. Após este procedimento, ainda é preciso fazer outra conversão: do sistema CIE-XYZ para o sistema CIE-xyY. As espécies são então representadas através das coordenadas de suas cores no plano xy e, como no processo anterior, são analisadas quanto as suas posições no diagrama, fornecendo informações quanto a especificação das espécies e identificando o comprimento de onda das cores monocromáticas predominantes em cada uma, como explica o Gráfico 8.

Gráfico 8 - Diagrama de determinação do comprimento de onda das cores monocromáticas.

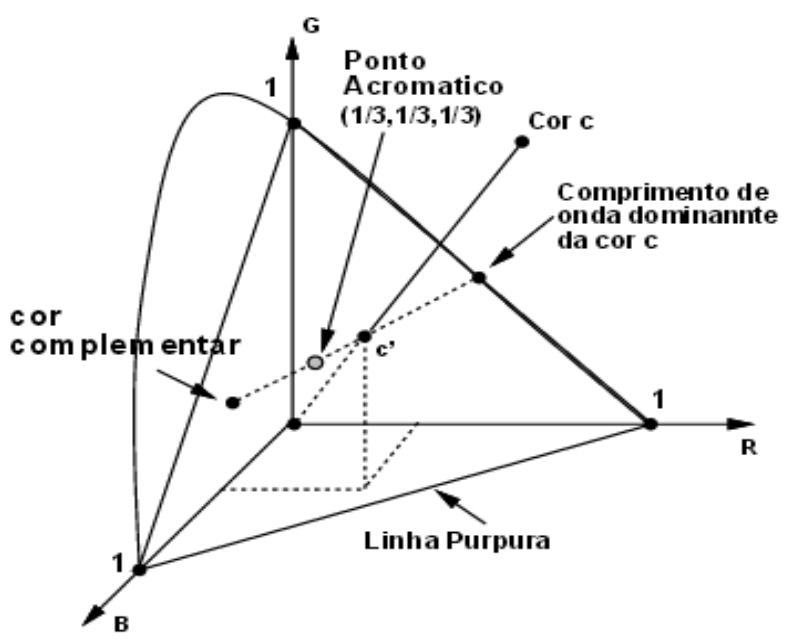

Fonte: Cavalcanti (2000).

De acordo com este gráfico esquemático, pode-se definir o comprimento de onda da cor dominante, traçando uma semi-reta partindo do ponto acromático e passando pela cor escolhida, neste caso, a cor c. A cor dominante pode ser entendida como uma cor pura do 

primárias

espectro, que produz a cor em questão ao ser misturada com a cor branca em proporções apropriadas.

\section{RESULTADOS E DISCUSSÃO}

A representação das cores no cubo de cores mostrou que todas as culturas obedecem a um padrão de localização, considerando pontos distintos dentro da mesma colônia ou mesmo comparando colônias diferentes. Como o experimento foi realizado formalmente em triplicata, os dados também são multiplicados por três. Sendo assim, além das comparações dentro de um processo experimental, realizou-se também analises comparativas entre um experimento e outro, o que possibilitou a comprovação e aumento da confiabilidade dos resultados.

Foram comparados cinco pontos selecionados aleatoriamente dentro de uma mesma placa. Este procedimento foi realizado com 0 intuito de comprovar que a cultura apresenta um padrão de homogeneidade no que diz respeito à sua cor. Ele foi repetido igualmente para as outras culturas estudadas, com o mesmo objetivo, obtendo êxito em todos.

A análise da relação entre as placas foi realizada adotando cada placa como um ponto. Para isto extraiu-se a média dos cinco pontos selecionados em cada colônia e, novamente, observou-se a regularidade na região de localização dos pontos que representam bactérias de mesma espécie, uma vez que eles se encontram consideravelmente próximos, acontecendo inclusive a superposição de alguns deles.

Para comprovar a possibilidade de identificação destas bactérias a partir de suas cores, além de mostrar que as mesmas obedecem a um padrão entre si, é importante demonstrar que elas também se diferenciam e se distanciam na representação no cubo de cores, o que habilita a continuação do processo, com a intenção de representá-las no diagrama de cromaticidade onde elas poderão ser identificadas de acordo com a área correspondente a cada espécie. 0 Gráfico 9 mostra a representação de todas as placas no cubo de cores em duas posições distintas e evidencia que cada tipo de bactéria ocupa uma região específica e única do espaço em questão. 
Gráfico 9 - Representação das localizações de todas as espécies no cubo de cores RGB.
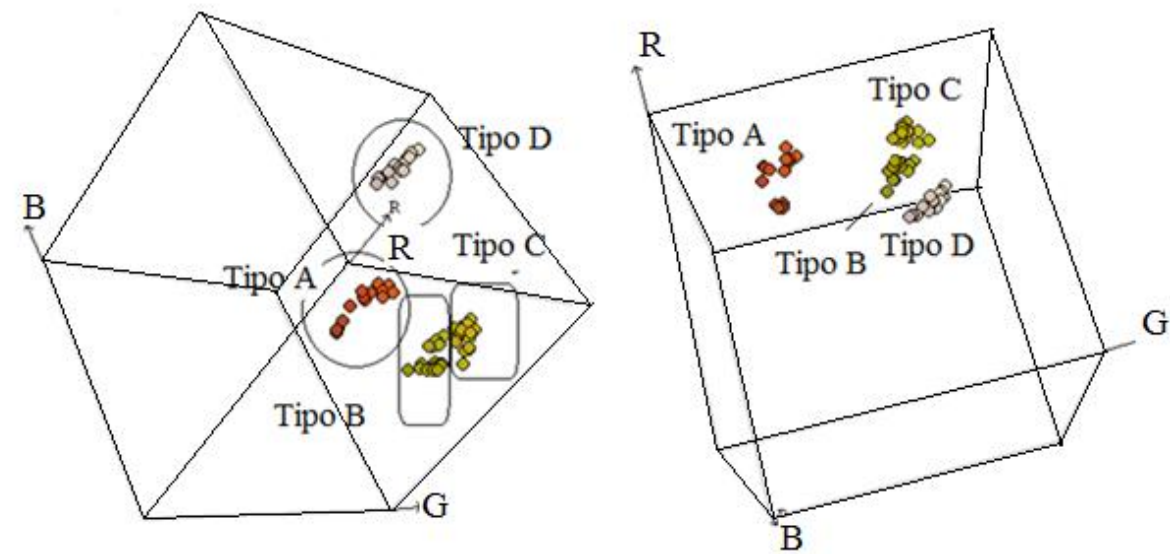

Fonte: Própria.

As colônias do tipo B e do tipo C, praticamente não podem ser distinguidas visualmente, nota-se claramente que elas possuem uma proximidade considerável no cubo. No entanto, se a perspectiva de visualização for alterada, uma vez que o cubo pode ser girado em torno de suas três dimensões, a separação entre elas pode ser mais claramente percebida, comprovando a distinção de regiões ocupadas por elas no espaço de cores.

0 processo de identificação foi realizado no diagrama de cromaticidade CIE-xyY. Todos os valores medidos em RGB foram convertidos para os sistemas de cores necessários, conforme descrito anteriormente neste artigo. Primeiramente, foram comparadas as informações dos três experimentos, para comprovar que os dados referentes à mesma espécie de bactéria se limitam a uma região de localização no diagrama, além de relacionarem entre si no que diz respeito à distância entre eles, o que foi verificado.

Para localizar as bactérias no diagrama de cromaticidade, foram calculadas as médias de todos os valores medidos (experimento realizado em triplicata onde foram analisados 5 pontos de cada placa em 5 placas de cada uma das 4 espécies estudadas, totalizando 300 pontos) para cada espécie com seus respectivos erros, mostrados na Tabela 3, de forma a transformá-los em um único ponto a ser representado no gráfico. 
Metodologia para identificação de bactérias do solo através da manipulação de cores primárias

Tabela 3 - Média dos valores RGB.

\begin{tabular}{ccccccc}
\hline Espécie & $\mathrm{R}$ & $\mathbf{G}$ & $\mathrm{B}$ & $\mathbf{\Delta R}$ & $\mathbf{\Delta G}$ & $\mathbf{\Delta B}$ \\
\hline $\mathrm{A}$ & 197 & 80 & 32 & 19 & 15 & 8 \\
$\mathrm{~B}$ & 171 & 163 & 14 & 9 & 10 & 3 \\
C & 197 & 174 & 13 & 9 & 9 & 3 \\
D & 217 & 201 & 185 & 10 & 14 & 9 \\
\hline
\end{tabular}

Fonte: Própria.

Estes pontos revelaram-se em localizações distintas e independentes no diagrama, além do ponto acromático, como mostra o Gráfico 10. Uma forma de demonstrar a especificidade de cada espécie é aplicar o método que define 0 comprimento de onda predominante em uma cor específica no diagrama. Para isso, conforme teoria já apresentada, basta traçar uma semi-reta iniciando no ponto acromático passando pelo ponto escolhido. 0 ponto de interceptação da mesma com a escala graduada de comprimentos de onda define 0 valor do comprimento de onda dominante na formação da cor em questão. 0 Gráfico 10mostra também que cada espécie é formada por uma cor específica e diferente das demais.

Gráfico 10 - Localização média de cada espécie no diagrama de cromaticidade e comprimento de onda predominante em cada espécie.
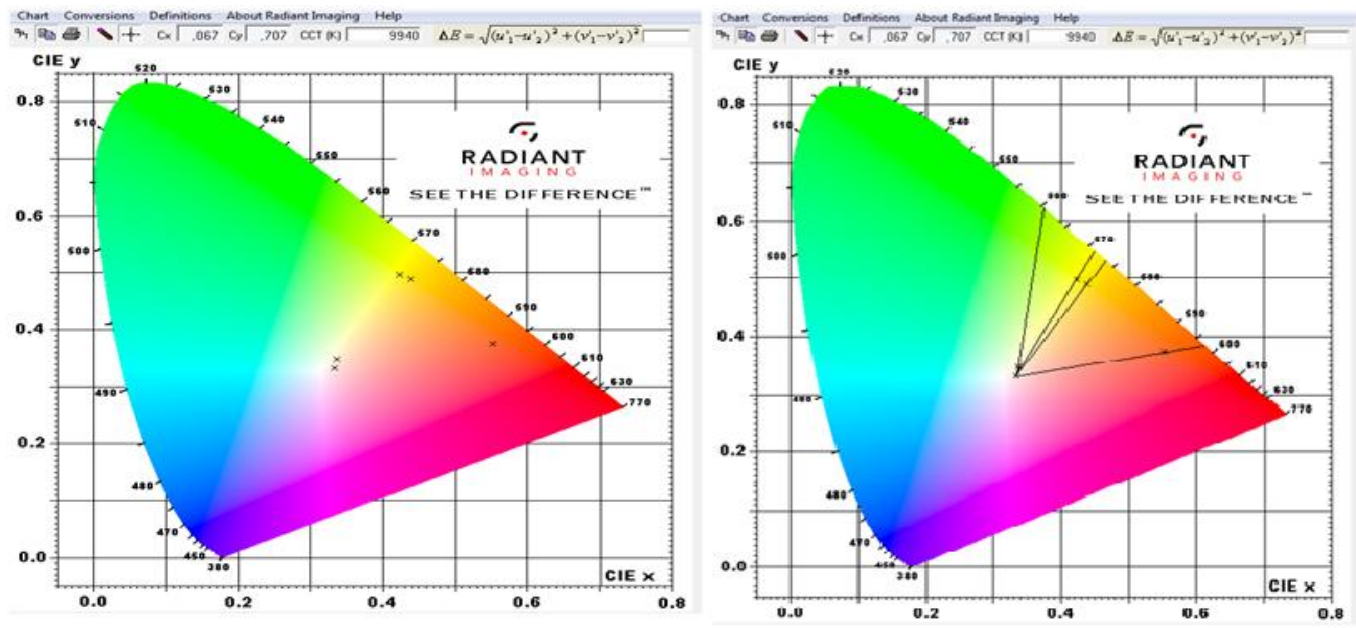

Fonte: Própria. 
Para restringir a região do diagrama a uma espécie única, possibilitando a identificação da mesma, construiu-se a área de abrangência de cada tipo de bactéria no diagrama de cromaticidade. Esta área foi obtida utilizando-se os valores dos erros máximos e mínimos de $\mathrm{x}$ e y retirados do desvio padrão de todas as medidas realizadas neste experimento, fazendo, destes pontos, coordenadas do plano que, consequentemente, resultam em um retângulo, pode ser observado no Gráfico ll:

Gráfico 11 - Regiões de identificação de cada espécie no diagrama de cromaticidade.

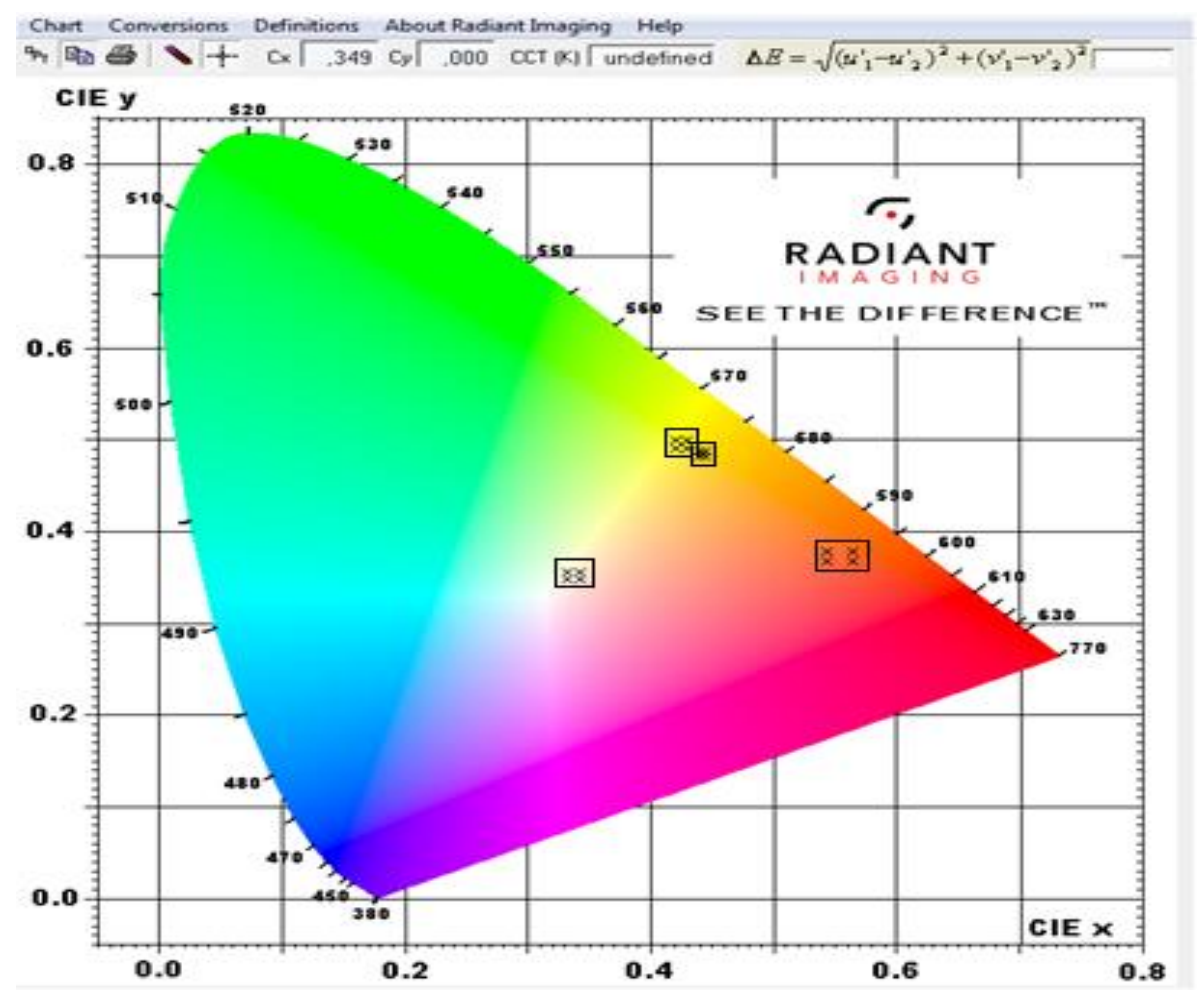

Fonte: Própria

Baseado na quantidade de medições realizadas e na repetição dos experimentos, podese considerar que cada região delimitada pelos pontos no diagrama acima representam tipos diferentes de bactérias, uma vez que todas as medidas com seus respectivos erros se encontram nas áreas de abrangência relacionadas a cada espécie estudada.

Sendo assim, ao submeter uma bactéria desconhecida a estes procedimentos e, tendo como resultado a localização dos dados que a representam no interior de alguma dessas regiões delimitadas no diagrama de cromaticidade, pode-se, com enorme margem de confiabilidade, afirmar que a mesma pertence à espécie correspondente a esta área, o que 
Metodologia para identificação de bactérias do solo através da manipulação de cores primárias

caracteriza estes processos como uma metodologia e um padrão fenotípico de identificação de bactérias. É importante ressaltar que a eficiência destes resultados foi observada apenas para as bactérias do solo da restinga de Massambaba em Arraial do cabo, fazendo-se necessário realizar mais experimentos para futuras generalizações.

\section{CONCLUSÃ0}

Este trabalho teve como objetivo o desenvolvimento de uma metodologia inovadora para identificação de bactérias do solo. Ficou demonstrado que cada cor correspondente a uma espécie estava contida em uma faixa de comprimentos de onda específica e totalmente distinta das demais, o que significa que cada cor resultante do experimento possui uma cor espectral predominante única.

0 objetivo principal, de identificação, foi obtido através da determinação de uma área específica para cada espécie no diagrama de cromaticidade. Esta área foi calculada maximizando os erros, uma vez que estes foram obtidos pelo desvio padrão de todas as medidas realizadas no experimento, garantindo que todos os pontos, mesmo com o maior desvio possível no resultado, se encontrarão dentro de sua respectiva região.

A região que corresponde a cada bactéria no diagrama de cromaticidade é considerada muito pequena em relação ao espaço de cores, conferindo uma particularidade aos pontos que se encontram dentro da mesma, validando o método de identificação, uma vez que se pode afirmar que todas as espécies abrangidas por áreas específicas são de uma mesma espécie.

\section{REFERÊNCIAS}

ADAMS, G.0.: FUFEYIN, P.T.: OKOR0, S.E.: EHINOMEN, I.. Bioremediation, Biostimulation and Bioaugmention: A Review. International Journal of Environmental Bioremediation \& Biodegradation, v.3, nº 1, p. 28-39, 2015.

ARGYRIA, A. A.: PANAGOU, E.Z.: TARANTILIS, P.A.: POLYSIOU, M.: NYCHAS, G.E.. Rapid qualitative and quantitative detection of beef fillets spoilage based on Fourier transform infrared spectroscopy data and artificial neural networks. Sensors and Actuators B: Chemical journal, v.145, p. 146-154, 2010. 
AZEVEDO, J. L.: ARAUJO, W. L.: MACCHERONI JR, W..Importância dos microrganismos endofíticos no controle de insetos. Em Controle Biológico, eds. Melo, I.S. e Azevedo, J.L.Embrapa Meio ambiente, v.3, 2000.

BRINDLEY, G.S.. The effects on colour vision of adaptation to very bright lights. Journal of Physiology, v.50, p. 122132, 1953.

CAVALCANTI, P. R..Introdução à computação gráfica. Rio de Janeiro, [s. n.]: 2000. Disponível em:http://orion.lcg.ufrj.br/compgrafl/downloads/apostila.pdf. Acesso em: 10 jul. 2014.

DELWICHE, S. R.: MASSIE, D. R.. Classification of wheat by visible and near-infrared reflectance from single kernels. Cereal Chemistry, v. 73, p. 399-405, 1996.

DINÂMICA para aprendizado do sensoriamento remoto. Centro Estadual de Pesquisas em Sensoriamento Remoto e Meteorologia. Universidade Federal do Rio Grande do Sul. Porto Alegre, [s.d.]. Disponível em: http://www.ufrgs.br/engcart/PDASR/formcor.html. Acesso em: 20 set. 2014.

ENVI - Guia do ENVI em Português. Sulsoft, 2000 . Diponível em http://www.ufrgs.br/engcart/PDASR/formcor.html. Acesso em 12 set. 2013.

GOMES, J.: VELHO, L..Computação gráfica: imagem. Rio de Janeiro: IMPA, 1998.

GONZALES, R. C.: WOODS, R. E..Processamento de imagens digitais. São Paulo: Edgard Blucher, 2003.

HANS, B.P.. Analysis of water in food by near infrared spectroscopy. Food Chemistry, v.82, p., 107-115, 2003.

JACK, R.: MACDONALD, L.: FREEMAN, K..Computer generated color: a pratical guide to presentation and display. New York: John Wiley \& Sons, 1994.

LEE, B.B.. The evolution of concepts of color vision. Neurociências, v. 4, p. 209-223, 2008.

LOPES, J. M. B..Cor e luz. Lisboa, maio 2003. Disponível em: http://disciplinas.ist.utl.pt/leiccg/textos/livro/Cor.pdf. Acesso em: 10 jul. 2014.

LOVLEY, D.R.: LLOYD, J.R.. Microbes with a mettle for bioremediation. Nature Biotechnology, v.18, p. 600-601, 2000.

MEYER, B.: ZOLLINGER, H.R..Colorimetria. [s.I.]: Clariant, 1998.

MIRALBES, C..Quality control in the milling industry using near-infrared transmittance spectroscopy. Food Chemistry, v. 88, p. 621-628, 2004.

REIS JUNIOR, F. B.: MENDES, I.C.: TEIXEIRA, K.R.S.: REIS, V.M.. Uso de ferramentas moleculares em estudos da diversidade de microrganismos do solo. Planaltina: Embrapa Cerrados, 2002. Disponível em: www.cpac.embrapa.br/download/278/t. Acesso em: 10 ago. 2014.

RESNICK, R.: HALLIDAY, D.: WALKER, J.. Fundamentos de física: ótica e fica moderna. v.4. 8. ed. Rio de Janeiro: LTC, 2010 .

RIBEIR0, M. C.. Microbiologia prática: Roteiro e manual. Editora Atheneu. Rio de Janeiro, 1993.

SHAH, M.P.. Environmental Bioremediation: A Low Cost Nature's Natural Biotechnology for Environmental Cleanup. Petroleum \& Environmental Biotechnology, v.5, p. 1-12, 2014. 
Metodologia para identificação de bactérias do solo através da manipulação de cores primárias

SOUTO, R. P.. Segmentação de imagem multiespectral utilizando-se o atributo matiz. São José dos Campos: INPE, 2000. Disponivel em: http://www.obt.inpe.br/pgsere/Souto-R-P-2000/publicacao.pdf. Acesso em: 01 out. 2014.

VELÁZQUEZ-FERNÁNDEZ,J.B.: MARTÍNEZ-RIZO, A.B.: RAMÍREZ-SANDOVAL, M.: DOMÍNGUEZ-0JEDA, D.. Biodegradation and Bioremediation of Organic Pesticides. In: Pesticides - Recent Trends in Pesticide Residue Assay. Published by Intech, 0pen Science 0pen minds, 2012, p. 253-272.

WERNER, J.S. (eds.).. Color Vision: Perspectives from different disciplines. Berlin; New York: de Gruyter, 1998.

WRIGHT, W.D.. The sensitivity of the eye to small colour differences. Procedures of Physical Society (London), v. 53, 1941.

WYSZECKI, G.: STILES, W.S.. Color Science: Concepts and methods, quantitative data and formulae. John Wiley \& Sons, New York, 1982. 